\title{
Chapter 4 \\ Rethinking the Frameworks of Psychology: What the Self Was and What it Was Not in Developmental Psychology
}

\begin{abstract}
The great snare of the psychologist is the confusion of his own standpoint with that of the mental fact about which he is making his report.
\end{abstract}

James, W. (1890, p. 196)

Throughout the history of psychology as an independent science, there have been many investigations concerning the self. Beginning from a deep, ascetic reflection by researchers themselves, "Who am I?," which has its roots in philosophical thinking, the main focus of psychological arguments is now upon the question, "Who are you?"-i.e., how can we understand the self of study participants? Developing many derivative concepts and a variety of methods, researchers exuberantly and confidently insist that they can understand our selves, not theirs. What researchers also aim for is to explain our behavior or our adjustment by means of terms containing the prefix "self-" - for example, self-evaluation or self-worth-and they sometimes indicate ways of looking at ourselves considered desirable.

The theoretical framework of the presentational self, introduced in the foregoing chapters, also attempts to construct our understanding of others. However, it does not depend on the pairing of questions from researchers with answers from study participants. It carefully describes what is occurring in the process of meaning construction and the effect this has on observers who look at the process with analytic intent. This schema is important to avoid the psychologists' fallacy that James (1890) warned of, in which we confuse what we understand with what we are going to describe. In this chapter, I first point out that our understanding of others, including self-representation, is our post hoc meaning construction from their meaning construction. With this understanding, I describe the fundamental principle of the presentational self, and discuss the methodological implications of the framework in relation to existing studies concerning the selves of children. 


\section{The Complex of Perspectives and Methods for Understanding Children's Selves}

Methods of psychological research are always accompanied by assumptions about the mind, and psychological inquiries into the self also rely on several presuppositions about what the self is, even if not a formal definition. To understand children's selves, which are also the object of my inquiry, researchers have developed rating scales consisting of items asking children about their lives or what they think of themselves (e.g., "I can do things as well as most other people"; Marsh, Smith, \& Barnes, 1985). In contrast with these attempts to represent children's selves by quantitative indices, other researchers have used open questions such as: "What kind of person are you?" or "What are you especially proud of about yourself?" (Damon \& Hart 1988, p. 81). Children's answers to these questions are classified into categories to show the "evidence" concerning the development of self-understanding.

These approaches share assumptions in common with a great deal of other psychological research. They focus on the self as an internal entity that is clarified through study participants' reflections triggered by questions posed by researchers (e.g., items in questionnaires, questions in interviews). We consider children's ratings or their answers to researchers' questions not as their evasion of examination, but a manifestation of what they maintain as their representations. Thus, the existing methods for understanding children's selves - that is, self-representation or self-understanding-serve to restrict what children's selves can be. It must be inside us and comparable among children in one occasion, and also stable in the flow of time. Historically, these assumptions have their origins partially in the dawning age of psychology, as in the definition by James (1890), ${ }^{1}$ who compared the self with our possessions. And contemporaneously, they work to bring about the legitimacy of psychological measurement and its usefulness for prediction. (For instance, appropriate self-understanding works as a foundation for better vocational selection.)

On these academic foundations, research supports a socially approved belief concerning child development and education, which aims at fostering children's self-understanding and self-evaluation. Maintaining children's adequate confidence in their own selves and nurturing appropriate self-understanding are considered indispensable aspects of children's social development. Working from a comprehensive understanding concerning the development of children's selves, researchers often recommend interventions for children who show self-evaluation or self-understanding that deviates from the standard. For example, Harter (1999) offered detailed explanations concerning the characteristics of children's self-representation in each developmental period, also indicating some points requiring attention for effective

\footnotetext{
${ }^{1}$ James (1890) defined self, or me, "In its widest possible sense, however, a man's Self is the sum total of all that he CAN call his" (p. 291)
} 
interventions. ${ }^{2}$ Supporting these recommendations, diverse educational efforts to promote children's self-understanding and respect their sense of self-worth are not limited to academics or educators but also provided to ordinary parents through many websites. ${ }^{3}$ In this way, our society considers school education a social apparatus for the development and elaboration of children's selves, and psychology and school education function as an academic-institutional complex that exerts an undeniable system of values on our viewing of children's selves.

\section{The Self is From Twofold Meaning Construction}

In contrast to the academic presupposition that children's answers to the standardized questions reflect their internal entities with some level of measurement error, we can see these answers as the results of participants' meaning construction that is triggered by the questions posed by researchers. When we ask children "Who are you?" we often expect them to define themselves using social categories or socially shared standards for evaluation, which also leads to their actions (Fig. 4.1). For example, when children describe themselves as "good at mathematics," this is considered to reflect their positive evaluations of themselves related to their everyday conduct, although their answers are not necessarily precise descriptions of

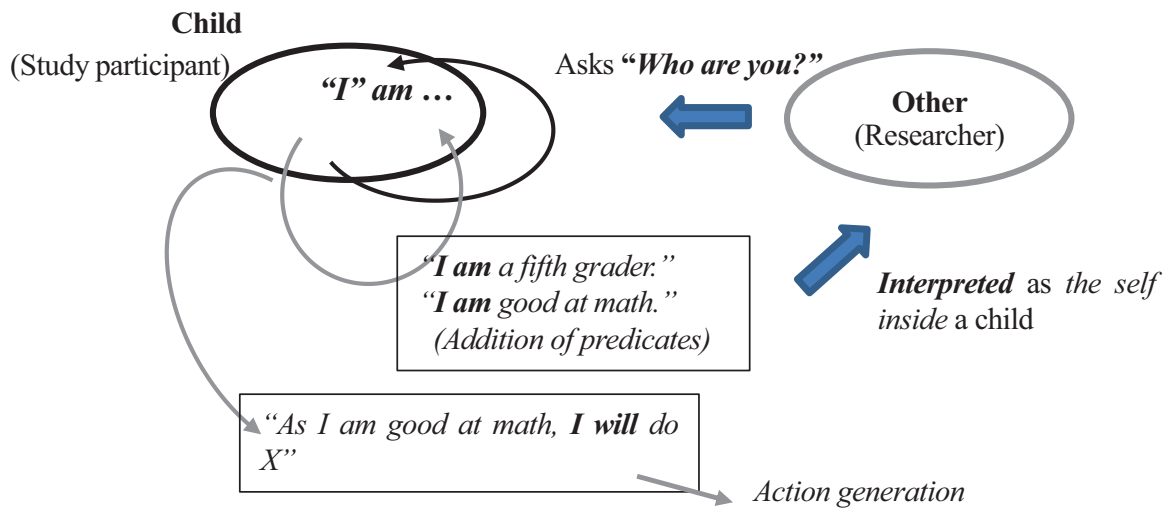

Fig. 4.1 The process of a child's answer to the question, "Who are you?"

\footnotetext{
${ }^{2}$ I do not insist on total abolition of these tests. Even if a standardized test shows the self clarified through the concern of researchers, educators, and policy makers, tests can serve as a viable and fair option for coping with the pressure to prove the efficiency of efforts, in the current social circumstances that require authoritative evidence to underpin educational efforts. However, it must be noted that this is a different type of meaning construction for children, compared with the meaning construction we observe in daily life.

${ }^{3}$ For example, "10 ways to nurture your child's self-concept" (http://calm4kids.org/10-ways-tonurture-your-childs-self-concept/)
} 
themselves. Actually, it is in this process that the self or the subject "I" becomes emergent, seeking for answers that are valid in the relationships between children and researchers.

When we are asked a question, it is open to many possible reactions, including ignoring the question. If we decide to present an answer considering the context, we explore a variety of possible answers and select one that suits the context well. When we think of our academic abilities, for example, we do not suddenly leap into a decision such as, "I am good at mathematics." Such a description is already the result of social exchanges in the past: i.e., questions from parents, comments from friends, and so forth. After such a trigger, we may re-construct our experiences in math class with boring emotions, confusion about difficult tasks, or sometimes pride in overtaking our friends. We can also see the self that works in such processes of constructing answers in the possible field of meaning construction and makes a position in relation to the question.

Research into developmental psychology has not focused on the process of meaning construction but only picked up the results of this process. However, the self-representation clarified through this process is the researchers' post hoc understanding of what children have constructed in relation to the interests of others. In other words, children's answers to researchers' questions are interpreted to become their "self-representation." For example, a child's statement "I am popular" in response to the question "What kind of person are you?" is cognizant that he or she has prior concerns in interpersonal relationships and keeps a positive view of himself or herself in this aspect. This interpretation is based on the interests shared in the academic community, and not necessarily those of the study participants. Looking at this framework of who discusses what, the discussion concerning children's selves is indivisible from the perspective that a researcher takes. It is observation by researchers that determines what self is, without the study participants' authorizing statement of "This is my self." Thus, the interpretive work of researchers operates to an extreme extent in their discovery of the self through participants' responses or actions.

In other words, this example shows that our understandings of children's selves are all related to their meaning construction and our post hoc meaning construction. The differences in the methods can be explained by the variety of foci we have. Our understanding of children is not self-evident from children's meaning construction, but rather emergent in our active observation and integration. Confirming this common nature concerning our understanding of children's selves, I will describe unique perspectives that the framework of presentational self offers in the next section.

\section{Formalizing the Presentational Self: Three Perspectives}

Perspective on the interaction observed in children's lives Although questions in the standardized methods can trigger children's meaning construction as I discussed above, we must consider the non-ubiquity of the reflections that these 
methods demand. In children's lives, they may rarely understand themselves in relation to a set of standardized questions. Items on standardized tests compress the complex processes children engage in life-not only in the content of reflection, but also in the needs of reflection-into one short sentence and ratings on a five- or seven-point scale.

There is another type of approach for young children's selves. Some studies have analyzed conversations in which young children and their family members talk about the children's experiences commencing when the children were around 2 years old. These studies focused on developmental changes in the structure of narratives, or the content of the conversations, with a special focus on children's autobiographical memories that is closely related to the development of selfunderstanding (see Nelson \& Fivush 2004, for review). In most of these studies, researchers directly asked children and their mothers to talk about topics compatible with their standards. With this method, they had the recordings of conversations that were comparable to each other in content and construction. However, as in many standardized tests, the meaning construction occurring in this process by children and mothers was also based on the researchers' interests.

In reality, the site in which children accomplish reflection is not the specific situation of testing, but their somewhat whimsical interactions with others around them. Children reflect on what they did and whom they met: that is to say, joys, troubles, or other miscellaneous issues. What we see there is not only garrulous talk with rich imagery of themselves, but short and sharp-witted utterances about their experiences, or, as I mentioned in the previous chapter, even complete silence in the flow of interaction can show their unique perspectives and "who they were." This leads to our understanding that one sincere way to understand children's selves is, if the child is young, to observe and interpret their ways of presenting their experiences in very ordinary situations in their lives. Although this orientation works at the cost of reproducibility and comparability of the data, it can reduce interference by the researchers' intentions and enables observation of a wide variety of children's meaning construction in natural settings.

Perspective on the self emerging in relationships From the beginning of my analysis, I focused on two types of interpersonal relationships in which we find the emergence of self: the interpersonal relationships described in the conversation and the interpersonal relationship between the child and the partner in conversation. Although they are always on the move, a fundamental system can be described as in Fig. 4.2.

First, the configuration of the child (e.g., Mina or Yuuma) and his or her friends that is constructed in the shared field of meaning construction is described as $\mathbf{A}$ in Fig. 4.2 below. As I discussed in Chap. 2 (see Fig. 2.2), the shared field of meaning also involves future infinity and past infinity. In the process of conversation, a variety of concepts or episodes are introduced to clarify the commonalities and differences among children and to construct a configuration of them. Even if the child does not describe himself or herself, the perspective from which he or she describes 


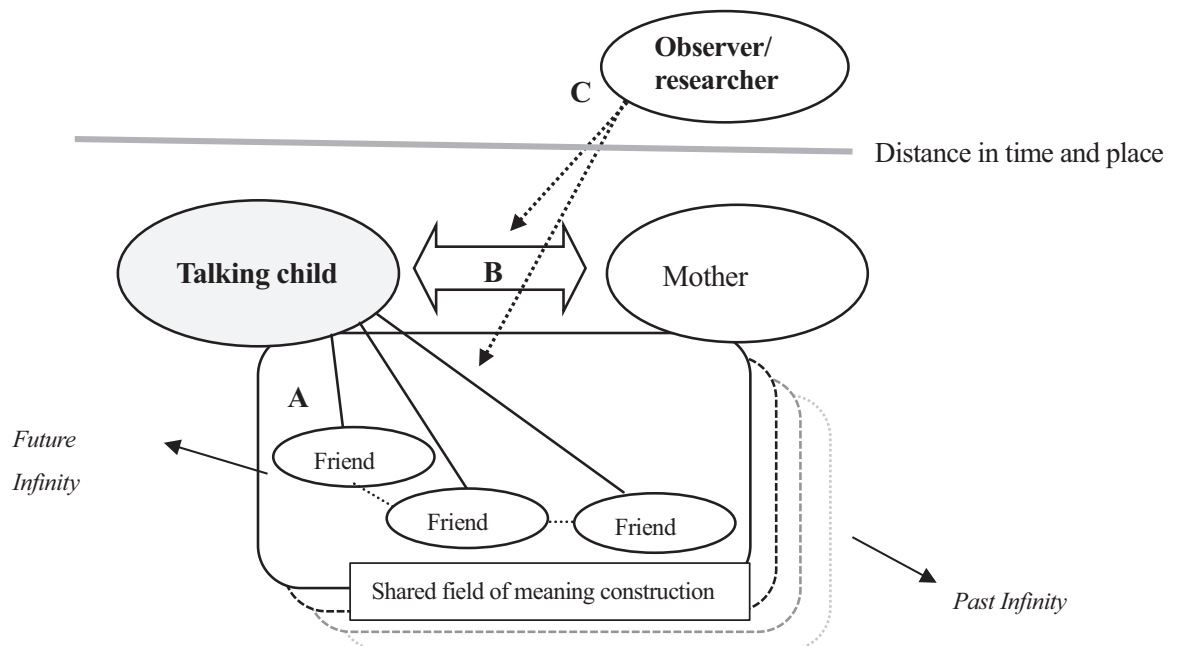

Fig. 4.2 Basic framework of the presentational self (Cited with modifications from Komatsu (2012, p. 359, Figure 1))

his or her friends becomes clear in the meaning construction, thus locating the child in the configuration.

Second, this description is also the process of constructing a relationship between the child and the partner in the conversation (B in Fig. 4.2). As we saw in the examples of conversation, the mother also contributes to the construction of the configuration in which her child is situated, and the field of meaning construction (the rectangle in Fig. 4.2) also depends on the mother. In this interaction, the child can also assume a position. For example, Mina made use of her right to assume a position to teach her mother about the children, as the events in hoikuen are what she experienced. On the other hand, when the topic is something the mother knows well, as in Excerpt 1.1 in which the child confirms that she was a cute baby, the relationship between the child and the mother becomes different and the mother assumes a position to clarify past events. Thus, the positioning between the child and his or her mother becomes clear in close relationship with their co-construction of the field of meaning.

Third, the analysis of the conversation I presented in the foregoing chapters entails the active observer who constructs and finds the presentation of the child in two types of relationship (A and B) through conversation. This is accomplished across the spatial and temporal distance between the site of conversation and the analysis ( $\mathbf{C}$ in Fig. 4.2). As was discussed in the previous section, this is our post hoc meaning construction from the traces of meaning construction developed in the conversation.

Perspective on the self as presentation, not representation In existing studies analyzing conversations between young children and their family members, researchers supposed that autobiographical memory is both constructed in the conversation and 
explains what is talked about in the conversation. Nelson (2003) used the terms narrative self-understanding (3-6 years of age) and cultural self-understanding (5-7 years) to describe what are constructed in these conversations. In other words, the process of conversation is supposed to be related to the representations children have and they explain the same types of actions in the resembling settings.

Our perspective described here conceptualizes the self in a different way. The framework abandons the idea of self as representation somehow inside children and considers the self a presentation that becomes clear through the complex arrangement described in Fig. 4.2. Though differing from the widespread presuppositions of modern psychology, the philosophical discussion concerning self tells us that presupposing the self as an entity is not an undeniable truth. According to Metzinger (2011), there is a variety of possible understandings of the self, including the no-self alternative. In other words, "there seems to be no empirical evidence and no truly convincing conceptual argument that supports the actual existence of 'a' self" (Metzinger, 2011, p. 279). From this viewpoint, psychologists' assumptions about the self are based only on intuitive soundness: that is, on commonsense (Komatsu, 2012).

\section{Modalities of Understanding Children's Selves}

Although I have offered a theoretical framework of the presentational self featuring its uniqueness in relation to existing research into developmental psychology, it still has commonalities with the majority of psychological methods and thinking, if we take the view that all these psychological methods use the traces of meaning construction by children. From this perspective, our understanding of children's selves is always our post-factum reconstruction from their meaning construction as I discussed above. To clarify this point and elaborate the framework, I describe the modalities of understanding children's selves (Table 4.1). Further, in this comparison, I introduce our understanding of the self on site for describing the nature of psychological data.

Understanding of children's selves from the result of meaning construction This is the most frequently used approach for understanding children's selves. As I discussed in the first part of this chapter, many studies use questionnaires or interviews, presuming that the self is an entity that is available for the meta-cognitive reflection needed for any response to such questions. In these studies, children's selves are presented as aggregated scores derived from ratings (e.g., scores of self-esteem measures) or the summaries of answers in interviews that are categorized into several groups (e.g., academic ability, outward appearance, personality characteristics, and more). The same applies to the analysis of mother-child conversations about their past experiences when researchers attempt to describe conversations using several concepts to summarize the characteristics of interaction. For example, researchers used the frequency of children or parents mentioning "internal states" or the extent to which they 
Table 4.1 Modalities of understanding children's selves

\begin{tabular}{l|l|l}
\hline $\begin{array}{l}\text { Mode of } \\
\text { understanding }\end{array}$ & Data used & $\begin{array}{l}\text { Researchers' post hoc meaning } \\
\text { constructions concerning the self }\end{array}$ \\
\hline $\begin{array}{l}\text { Understanding from } \\
\text { the result of meaning } \\
\text { construction }\end{array}$ & $\begin{array}{l}\text { Static configuration of } \\
\text { several indices } \\
\text { Bearing no relationship in } \\
\text { time and totally detached } \\
\text { from context } \\
\text { No consideration of the } \\
\text { relationships or the contexts } \\
\text { in which data are produced }\end{array}$ & $\begin{array}{l}\text { Describing the stable self (e.g., self- } \\
\text { understanding, self-evaluation) inside } \\
\text { children } \\
\text { Comparison of results from other } \\
\text { children or other instances } \\
\text { Open to a variety of understandings } \\
\text { concerning the process children had in } \\
\text { self-representation as described in the } \\
\text { assessment } \\
\text { (very open but fallacious) }\end{array}$ \\
\hline $\begin{array}{l}\text { Understanding from } \\
\text { the process of } \\
\text { meaning construction }\end{array}$ & $\begin{array}{l}\text { Recordings of interaction or } \\
\text { narratives that maintain the } \\
\text { change in time and } \\
\text { relational nature } \\
\text { Data are specific to time and } \\
\text { space }\end{array}$ & $\begin{array}{l}\text { Figuring out the self that emerges in } \\
\text { meaning construction } \\
\text { Understanding of relational achievements } \\
\text { A variety of interpretations and } \\
\text { understandings of interaction are possible } \\
\text { (open and relative) }\end{array}$ \\
\hline $\begin{array}{l}\text { Understanding } \text { on site } \\
\text { One time only and } \\
\text { embedded in unique } \\
\text { background } \\
\text { Microgenesis of meaning in } \\
\text { ongoing experiences }\end{array}$ & $\begin{array}{l}\text { Impossible for a third person and } \\
\text { possible only for the person concerned } \\
\text { (genuine but closed) }\end{array}$ \\
\hline
\end{tabular}

introduced new information into the conversation to figure out what happened in the conversation (see Nelson \& Fivush 2004; Fivush, Haden, \& Reese, 2006, for review). These are also accumulations of fragmented pieces of interaction.

These methods describe a configuration of elements (e.g., scores on standardized measurements, numbers of each type of answer in open-ended interviews), but they do not suppose how these meaning constructions were achieved. They also ignore many types of relationships created by researchers and study participants. When children are confronted with a questionnaire, they have a variety of possible reactions, though these are almost invisible. Some of them will be interested in what happens in the course of research, but for others these are boring tasks. Some children may become anxious about what the test is assessing. After these encounters, children commence their meaning construction to answer the questionnaire items. In most studies concerning mother-child conversations, participants who are asked to talk about their experiences have a variety of reactions, as it is actually very unnatural to be asked to talk on specific topics.

The very composition of this genre of data makes it easy to construct, reproduce, and sometimes fabricate them. These data are also quite open to a variety of post hoc meaning construction because they are questions paired with simple answers, independent of the context of real lives. Researchers can construct their stories to 
explain why children answer in a certain way. However, these post hoc meaning constructions often depend on the knowledge or orientation of whoever is reading the data. This openness can also lead to mistaken understandings, and this disadvantage becomes prominent when constructed from data fabricated to make a positive impression on observers (e.g., fake ratings in a questionnaire). ${ }^{4}$

In these attempts, fixed stimuli for this meaning construction (e.g., items in questionnaires) are considered to guarantee the objectivity of the results and enable us to compare the profiles of multiple children. Using the framework given in Fig. 4.2, I illustrate this process as in Fig. 4.3 below.

As Valsiner (2017) pointed out, research becomes possible by constructing a shared field of meaning between researchers and participants who construct their identities in the move to their meeting place. Questionnaires and interviews are examples of such shared fields, and these are also the sites where researchers and participants negotiate their positions, as I described above for children's encounters with questionnaires. Participants construct meaning here in relation to the items shown to them - that is, their answers to questionnaires are in the ways they interact with items (A) and the other people conducting the research (B). However, researchers ignore these dynamics or this context, due to the fact that they use standardized, common questions and move to a position from which they appear to look only at the results of meaning construction as what shows children's selves (e.g., selfunderstanding), independent of context ( $\mathbf{C}$, see the upward movement of the researcher in Fig. 4.3). This shows that standardized methods of psychology are

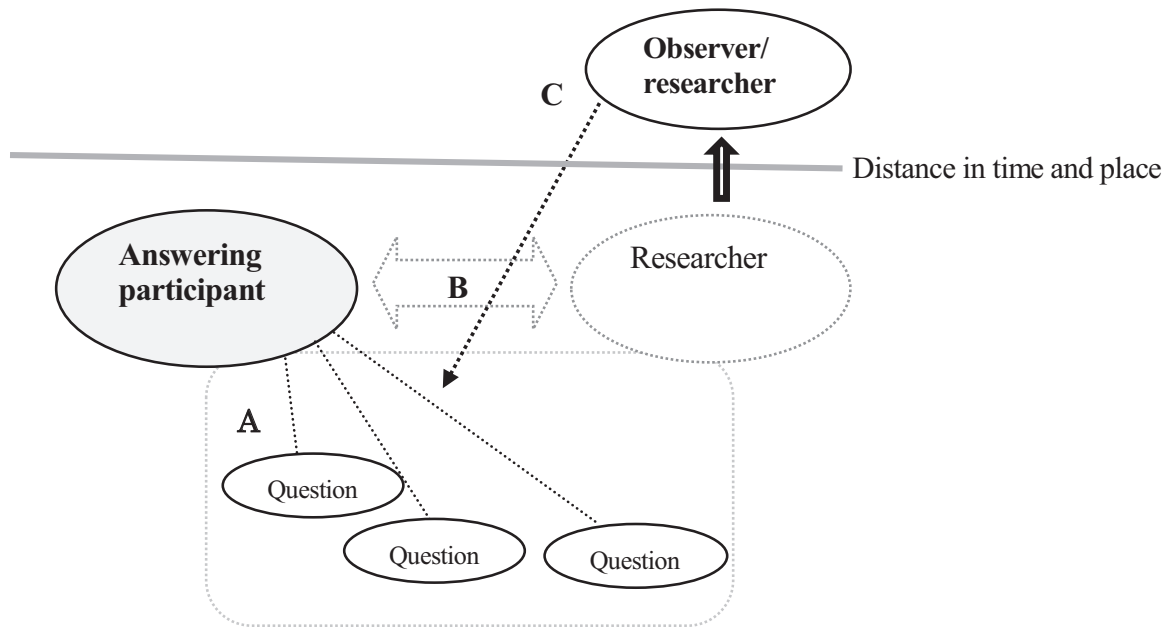

Fig. 4.3 Procedure of psychological assessment by standardized methods (Cited with modifications from Komatsu (2012, p. 362, Figure 2))

\footnotetext{
${ }^{4}$ This resembles the urge to take impressive pictures for social media in order to be perceived as happy or successful. Ease of construction and openness to meaning construction are at the foundation of this.
} 
organized in disregard of many aspects of relationships, shown by dotted lines in Fig. 4.3, that were actually involved in the process of research.

Understanding of children's selves from the process of meaning construction In contrast with the simple framework of standardized methods described above, recordings of what children do or say are basically organized fragments cut from a flow of time, and they typically maintain the relationships among children's behaviors (or sayings) in time.

Although narratives can be total fraud with no concrete foundation in children's lives, they all are meaning constructions and we can attempt post hoc meaning constructions from these data. The framework of the presentational self is based on such process-inclusive data and is a stance inclusive of the dynamics at work in meaning construction. However, because the data are only extracts from daily lives, they are also open to other interpretations. Figuring out the selves in recorded conversations is possible in post hoc meaning construction but my discussion is not necessarily an absolute one, and our post hoc meaning constructions concerning individual interactions often compete with each other. In other words, the presentation of our experiences or understandings is open and involves relativity, as it is detached from specific context. For this reason, we must consider the understanding of children's selves on site discussed below and distinguish it from our post hoc understanding.

Understanding of children's selves on site Understanding of children's selves is not limited to research in psychology. Our experiences are embedded in a unique, onetime context and our understanding of self and others is also performed in this setting. In a variety of interactions, we always pay attention to what others do, and we behave in relation to what we understand from these observations. Thus, parents and teachers understand what children care about or intend to do from their conduct or utterances in their interactions with children, even though they do not use the word "self." For example, in the examples of conversation discussed in Chap. 3, mothers construct their own understandings of their own child's experiences in order to participate in the conversation, as a microgenesis of meaning which is "occurring as the person faces the ever-new next time moment in the infinite sequence of irreversible time" (Valsiner, 2007, p. 301).

Though I described these interactions in fine detail, our understanding of children's selves is different from the mothers' understanding at the site (on site) of the conversation. The understanding on site reflects a history between the partners in interaction; especially among family members, relationships last for a long time and they experience a variety of events together, both in positive and negative ways. When Mina and her mother talk about their visit to a zoo in the past (Except 1.1), what a particular zoo may represent is different for them and for us. The mothers' and children's semiotic processes required to understand the partner on site work in 
relationship with complex affective reactions that are the results of these past experiences. Thus, understanding of others on site is embedded in context in multiple ways, and of course it has a subjective nature: i.e., closed to researchers. We can ask mothers to look back and narrate their understanding of their children in the conversation, but these stories are already different from their understanding that has been at work in the conversation.

If we convert this understanding of others into the understanding of ourselves on site, this mode corresponds with the following discussion from Mead (1934).

The "I" is the response of the organism to the attitudes of the others; the "me" is the organized set of attitudes of others which one himself assumes. The attitudes of the others constitute the organized "me," and then one reacts toward that as an "I." (p. 175)

When we modify the schema of the presentational self into the model of our construction of ourselves, in which an interacting person himself or herself takes the position to find his or her behavior from the viewpoint of an assumed other, it constructs a feedback loop to clarify the self as "me" in relation to the acting "I" (Fig. 4.4).

In this example, the distance between the shared field of meaning construction (the big rectangle) and who observes it disappears. When we interact with objects or others (A), we assume somewhat generalized others and an "organized set of attitudes" (B). What is also working in this process is the "I" that is constituting "me" in the process and creating reactions to others' responses $(\mathbf{C})$. Although heavily transformed from the original form in Fig. 4.2, this shows that the characteristics of the framework that describes how we find our self through interaction are also related to the idea of the presentational self.

Fig. 4.4 A description of self-perception as performed on site (Cited with modifications from Komatsu (2012, p. 363 , Figure 3))

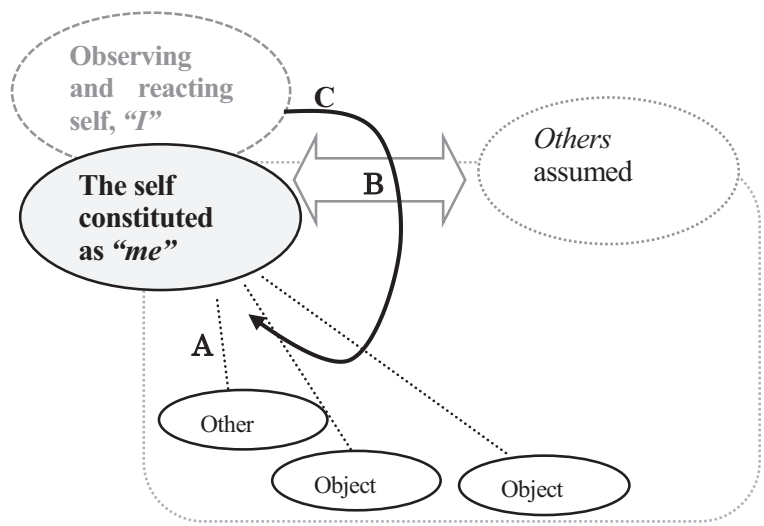




\section{Comparing Understandings of Children's Selves}

Table 4.1 shows the gap between psychological understandings of the self and the understanding of the self on site. First, in my discussion here, children's or their family members' understandings of children's selves are based on their understanding on site, while psychological understandings are usually derived from the meaning construction by children detached from context, even when recorded in detail. Two types of psychological understanding are also different from each other.

Researchers use standardized methods in which interactions are restricted and contexts are ignored, because of the presupposition that the self is individual and stable in time. For example, in the studies of conversations between young children and their parents, individual differences in parental elaboration are considered important for the construction of the children's detailed autobiographical memories and related to their understanding of self and others (e.g., their performance in the false belief task) (Fivush et al., 2006). In these approaches, understanding children's selves from the result of meaning construction is useful when believed to work toward favorable development of children. Despite this possible practical utility, this is merely one perspective for viewing children's selves.

The contrasts of these multiple understandings are observable in the meaning of silence in conversation, which I touched upon in the foregoing section. Keeping silent after a question from researchers usually means no data in interviews or questionnaires that attempt to construct understanding from the results of meaning construction, and data from such participants is often excluded before final analysis. However, as we also experience in our own conversations, silence serves as a powerful tool for meaning construction in relationships. Mothers who talk with their children actually feel this in their interactions. Excerpts 4.1 and 4.2 are from interviews ${ }^{5}$ that asked mothers of 3 year-old children about their daily conversations concerning their children's experiences at yochien (Komatsu, 2012; Komatsu \& Noguchi, 2001).

\section{Excerpt 4.1}

(Participant A) As I pick him [her child] up, teachers tell us some stories about what happened during the day, and I ask him about them. He just says, "Yeah, we did that" and that's all. I'd like to hear more but he says, "[I] don't know," "[I] forgot," or something. I guess he is tired of answering, or rather, from his perspective, it may be that he is conscious that "I attend yochien, not mom."

(Cited with modifications from Komatsu (2012, p. 364, Excerpt 1), original Japanese is in Komatsu \& Noguchi, 2001, p. 74)

\footnotetext{
${ }^{5}$ Original recordings and transcripts are in Japanese. Translations into English were made by the author.

${ }^{6}$ In the original utterance in Japanese, the mother says "It may be because he had a consciousness that the yochien is mine." The translation shown in Excerpt 4.1 was determined with the help of native English speakers, to keep the nuance of what the mother was intending (Komatsu, 2012).
} 


\section{Excerpt 4.2}

(Participant C) Of course, I'd like to know his behavior or his habits [at yochien], sure. But I feel I shouldn't know them in too much detail. [Several turns omitted] From the day he began to attend yochien, he's been independent from me and has, yeah, his own time and his own relationships, finally. Then, if parents, well, I can't explain it clearly, are over-interested and interfere with their children, I fear it'll be too much for him. [Several turns omitted] Now, he has his friends, there is his teacher, and he says "It's my yochien." So I hope he can handle it [the yochien] on his own.

(Cited with modifications from Komatsu (2012, p. 365, Excerpt 2), original Japanese is in Komatsu \& Noguchi, 2001, p. 73).

What appears in mothers' understanding of their children's conduct or utterances is considered an appearance of children's uniqueness in relation to their mothers. It can be interpreted as mothers finding out their children's selves in their relationships, as their understanding of their children is described with emphasis on the pronouns "I" and "my" of the child. However, in these excerpts, a mother (Participant A) finds evidence of the development of her son's self in not talking much about his experiences. Participant $\mathrm{C}$ believes it is important for her to not ask about her child's experiences in order to support her child's own style of living, which cannot be shared. Thus, in aspects of daily life, the absence of a detailed story can also clarify or emphasize a child's self. Although the possibility of generalizing these beliefs is unclear, it shows that the self in conversation is never fully grasped by analysis that quantifies what was told there. This example also shows that our focusing on the relational aspects and process of the meaning construction contains the possibility of our edging up to the understanding of children's selves on site, though there remains a qualitative gap that is difficult to overcome.

\section{Conclusion: An All-Inclusive Perspective for Children's Selves}

The concept of the presentational self is constructed including the process of meaning construction in our relationships, and even entails the observer who discovers the self in the semiotic activities. This orientation might be criticized as neglecting the premise of psychology that a person has some static entity in his or her psyche that can be clarified in objective ways through questioning. As I showed in Fig. 4.3, such standardized methods of psychology ignore some important aspects of our meaning construction that are also at work in children's answering the questions from researchers. Such ignorance is related to their desire for objective and replicable methods of inquiry, and a variety of latent responses of children to the questions are discarded as meaningless.

These can be an approach for our minds, but they are not the only way. The framework of the presentational self deliberately and carefully attempts to include many, if not all, of the elements related to the meaning construction that children attempt in their daily lives. Its process-oriented nature and the inclusion of the observer into the schema render any claim of objectivity difficult, but also enable 
our access to the complexity and the exquisiteness achieved through the function of signs, as I described in Chap. 3.

After the elaboration of its position in relation to other methods, the next step in developing this theoretical framework is applying it to other instances. For this purpose, I examine elementary school children's stories about their experiences, written as an activity within school education in Japan, from the perspective of the presentational self.

Open Access This chapter is licensed under the terms of the Creative Commons Attribution 4.0 International License (http://creativecommons.org/licenses/by/4.0/), which permits use, sharing, adaptation, distribution and reproduction in any medium or format, as long as you give appropriate credit to the original author(s) and the source, provide a link to the Creative Commons license and indicate if changes were made.

The images or other third party material in this chapter are included in the chapter's Creative Commons license, unless indicated otherwise in a credit line to the material. If material is not included in the chapter's Creative Commons license and your intended use is not permitted by statutory regulation or exceeds the permitted use, you will need to obtain permission directly from the copyright holder.

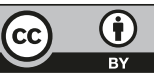

